different conditions. Using this breath collection method, there is no role for the use of breath $\mathrm{H}_{2} \mathrm{~S}$ or $\mathrm{HCN}$ in the diagnosis or monitoring of pneumonia in critical illness.

\begin{tabular}{|c|c|c|c|}
\hline $\begin{array}{l}\text { Cause of } \\
\text { pulmonary } \\
\text { infiltrates }\end{array}$ & $\begin{array}{l}\text { Number } \\
\text { of patients } \\
(\%)\end{array}$ & $\begin{array}{l}\text { Median } \mathrm{H}_{2} \mathrm{~S} \\
\text { concentration } \\
\text { (range) (ppb) }\end{array}$ & $\begin{array}{l}\text { Median HCN } \\
\text { concentration } \\
\text { (range) (ppb) }\end{array}$ \\
\hline Pneumonia & $12(43)$ & $1.18(0.61-3.47)$ & $1.13(0.50-1.41)$ \\
\hline Pulmonary oedema & $6(21)$ & $1.32(0.30-2.57)$ & $1.09(0.42-3.87)$ \\
\hline Aspiration lung injury & $4(14)$ & $1.31(1.09-1.54)$ & $0.85(0.63-2.73)$ \\
\hline Atelectasis & $3(11)$ & $0.74(0.42-2.51)$ & $1.57(0.47-10.11)$ \\
\hline $\begin{array}{l}\text { ARDS (cause other } \\
\text { than pneumonia) }\end{array}$ & $2(7)$ & $0.76(0.54-0.98)$ & $0.62(0.50-0.75)$ \\
\hline Other & 1 (4) & 0.22 & 0.42 \\
\hline
\end{tabular}

\section{P147 CURRENT SMOKERS FACE INCREASED RISK OF ACUTE LUNG INJURY POST OESOPHAGECTOMY COMPARED TO FORMER SMOKERS- IMPLICATIONS FOR THERAPY AND TRIAL DESIGN?}

${ }^{1}$ RCA Dancer, ${ }^{2} \mathrm{D}$ Parekh, ${ }^{3} \mathrm{CS}$ Calfee, ${ }^{4} \mathrm{DF}$ McAuley, ${ }^{2} \mathrm{GD}$ Perkins, ${ }^{1} \mathrm{DR}$ Thickett; ${ }^{1}$ University of Birmingham, Birmingham, UK; ${ }^{2}$ University of Warwick, Warwick, UK; ${ }^{3}$ UCSF School of Medicine, San Francisco, USA; ${ }^{4}$ Queens University Belfast, Belfast, UK

\subsection{6/thoraxjnl-2013-204457.297}

Introduction Patients undergoing oesophagectomy have $\sim 25 \%$ risk of developing post-operative Acute Lung Injury (ALI). A recent meta-analysis showed that smoking cessation prior to an operation reduces the risk of respiratory complications [1]. We hypothesised that current smokers would have an increased risk of ALI post-oesophagectomy compared with former smokers. Methods We analysed data from 14 current smokers and 37 former smokers recruited to the translational sub-study of the BALTI prevention trial. Extravascular Lung Water Index (EVLWI) and Pulmonary Vascular Permeability Index (PVPI) were measured using PICCO. Plasma and Bronchoalveolar lavage fluid (BALF) cytokine levels were measured by ELISA.

Results Current smokers were significantly younger and had a lower BMI than former smokers. Current smokers were more likely to develop post-operative ALI which required ventilation but there was no difference in the rate of respiratory infection. PVPI was significantly higher immediately post op and on day 1 post op and EVLWI was significantly higher on day 1 post op in current smokers (see table).

Plasma levels of FAS ligand were significantly lower in current smokers pre-op, post-op and on day 1 post-op. Pre-op plasma levels of sICAM1 were significantly higher in current smokers but there was no difference in post-op levels. Plasma levels of IL-17 were lower pre-op, post-op and on day 1, although only the post-op difference reached significance. In BAL, levels of VEGF were significantly lower and levels of IL1ra and TNFR1 were significantly higher in current smokers (see table).

Conclusion Current smokers have a higher risk of Acute Lung Injury following oesophagectomy than former smokers. This finding is supported by higher post-operative levels of extravascular lung water and pulmonary vascular permeability and differences in both plasma and BAL cytokines in current smokers.
Our data highlights the importance of encouraging patients to stop smoking prior to major surgery as well as the need to control for smoking history in trials aiming to ameliorate lung injury in this patient group.

\section{REFERENCES}

1. Wong, J. et al. Short-term preoperative smoking cessation and postoperative complications: a systematic review and meta-analysis. Can J Anaesth, 2012. 59(3): 26879

\begin{tabular}{|c|c|c|c|c|}
\hline & & $\begin{array}{l}\text { Current } \\
\text { Smokers } \\
(n=14)\end{array}$ & $\begin{array}{l}\text { Former } \\
\text { Smokers } \\
(\mathrm{n}=37)\end{array}$ & P-value \\
\hline \multicolumn{2}{|l|}{ Age (Years) } & 48 & 65 & $<0.001$ \\
\hline \multicolumn{2}{|l|}{ BMI $\left(\mathrm{kg} / \mathrm{m}^{2}\right)$} & 22 & 26 & 0.002 \\
\hline \multicolumn{2}{|c|}{ Developed ALI - n (\%) } & $6(43)$ & $6(16)$ & 0.045 \\
\hline \multicolumn{2}{|c|}{ Developed respiratory infection - $\mathrm{n}(\%)$} & $5(35)$ & $12(32)$ & 0.824 \\
\hline \multirow[t]{3}{*}{ EVLWI $(\mathrm{ml} / \mathrm{kg})$} & Pre-op & 8.3 & 7.8 & 0.520 \\
\hline & Post-op & 11.0 & 9.3 & 0.191 \\
\hline & Day 1 & 9.8 & 7.9 & 0.040 \\
\hline \multirow[t]{3}{*}{ PVPI } & Pre-op & 2.13 & 1.74 & 0.151 \\
\hline & Post-op & 2.43 & 1.97 & 0.050 \\
\hline & Day 1 & 2.09 & 1.69 & 0.008 \\
\hline \multirow[t]{3}{*}{ Fas Ligand $(\mathrm{pg} / \mathrm{ml})$} & Pre-op & 21.85 & 36.78 & 0.001 \\
\hline & Post-op & 17.62 & 30.73 & 0.001 \\
\hline & Day 1 & 9.05 & 18.38 & $<0.001$ \\
\hline \multirow[t]{3}{*}{ sICAM-1 (ng/ml) } & Pre-op & 103.52 & 56.95 & 0.005 \\
\hline & Post-op & 51.38 & 43.01 & 0.199 \\
\hline & Day 1 & 100.38 & 88.00 & 0.226 \\
\hline \multirow[t]{3}{*}{ IL-17A (pg/ml) } & Pre-op & 8.42 & 55.66 & 0.088 \\
\hline & Post-op & 2.64 & 36.84 & 0.043 \\
\hline & Day 1 & 8.26 & 83.57 & 0.084 \\
\hline VEGF (pg/ml) & BAL & 94.05 & 153.40 & 0.016 \\
\hline IL1ra (pg/ml) & BAL & 50.99 & 9.83 & 0.007 \\
\hline sTNFR1 (pg/ml) & BAL & 270.5 & 168.5 & 0.042 \\
\hline
\end{tabular}

\section{P148 ASPIRIN THERAPY IS ASSOCIATED WITH REDUCED MORTALITY IN PATIENTS WITH ACUTE LUNG INJURY}

${ }^{1}$ AJB Boyle, ${ }^{2}$ SD Digangi, 'LM Mottram, 'UH Hamid, 'LM McNamee, 'GW White, ${ }^{1} \mathrm{UMMC}$ Cross, ${ }^{1} \mathrm{JM}$ McNamee, ${ }^{1} \mathrm{CO}$ O'Kane, 'DFM McAuley; ${ }^{1}$ Queen's University Belfast $/$ Royal Victoria Hospital, Belfast, United Kingdom; ${ }^{2}$ AO Citta' della Salute e della Scienza, Turin, Italy

\subsection{6/thoraxjnl-2013-204457.298}

Introduction Platelet activation has a role in the pathogenesis of ALI. Observational data suggests aspirin treatment may prevent the development of ALI in critically ill patients. However, it is unknown if aspirin usage alters outcomes in patients with established ALI.

Methods All patients with ALI were identified prospectively in a single large regional medical and surgical ICU between December 2010 and July 2012. Demographic, clinical, and laboratory variables were recorded. Aspirin usage, both pre-hospital and during Intensive Care Unit (ICU) stay, was included. The primary outcome was ICU mortality. We used univariate and multivariate analyses to assess the impact of these variables on ICU mortality.

Results Two hundred and two patients with ALI were included. $56(28 \%)$ of these received aspirin either pre-hospital, in ICU, 
or both. Using multivariate logistic regression analysis, aspirin was found to be protective for ICU mortality. Additional factors that predicted ICU mortality for patients with ALI were vasopressor use and APACHE II score (Table).

Conclusion Aspirin usage is associated with reduced mortality in patients with ALI. Whilst trials are ongoing to assess if aspirin can prevent ALI, these new data support the need for a clinical trial to investigate if aspirin improves outcomes in patients with established ALI.

\begin{tabular}{lll}
\hline \multicolumn{2}{l}{ Abstract P148 Table 1.} & \\
\cline { 2 - 3 } Predictor & OR $[95 \% \mathrm{Cl}]$ & p-value \\
\hline Age & $1.02[1.00-1.05]$ & 0.079 \\
APACHE II score & $1.07[1.02-1.13]$ & 0.010 \\
Aspirin use & $0.42[0.18-0.96]$ & 0.040 \\
Pa02 / Fi02 ratio & $0.97[0.93-1.00]$ & 0.085 \\
Vasopressor use & $2.09[1.05-4.16]$ & 0.036 \\
\hline
\end{tabular}

\section{Pulmonary hypertension: mechanisms and treatment}

\section{P149 EFFECT OF MACITENTAN ON PULMONARY ARTERIAL HYPERTENSION-RELATED HOSPITALISATIONS: RESULTS FROM THE RANDOMISED CONTROLLED SERAPHIN TRIAL}

${ }^{1} \mathrm{G}$ Coghlan, ${ }^{2} \mathrm{RN}$ Channick, ${ }^{3} \mathrm{U}$ Rubin, ${ }^{4} \mathrm{~N}$ Galiè, ${ }^{5} \mathrm{~L}$ Perchenet, ${ }^{6} \mathrm{G}$ Simonneau; ${ }^{1}$ Royal Free Hospital, London, UK; ${ }^{2}$ Massachusetts General Hospital, Boston, USA; ${ }^{3}$ University of California, San Diego, USA; ${ }^{4}$ University of Bologna, Bologna, Italy; ${ }^{5}$ Actelion Pharmaceuticals Ltd, Allschwil, Switzerland; " ${ }^{6}$ Hôpital Universitaire de Bic\tre, Le KremlinBic \tre, France

\subsection{6/thoraxjn-2013-204457.299}

Introduction and objectives Macitentan, a novel dual endothelin receptor antagonist with sustained receptor binding, significantly reduced the risk of morbidity and mortality in pulmonary arterial hypertension (PAH) patients in the SERAPHIN trial (NCT00660179), the first event-driven outcomes trial in PAH. The effect of macitentan on the risk of PAH-related hospitalisation was evaluated in this study.

Methods In SERAPHIN, a multicentre, double-blind, placebocontrolled trial in PAH, patients (aged $=12$ years) in WHO functional class II-IV were randomised $(1: 1: 1)$ to oral macitentan $3 \mathrm{mg}, 10 \mathrm{mg}$, or placebo once-daily. Time to death due to $\mathrm{PAH}$ or hospitalisation for PAH up to end of treatment (EOT), and time to hospitalisation for PAH up to EOT were evaluated (KaplanMeier analysis). Treatments were compared using log-rank tests. Annual rates of PAH-related hospitalisations and inpatient hospital days up to EOT were also assessed.

Results For the 742 patients randomised, the median treatment duration was $>2$ years. The risk of death due to PAH or hospitalisation for PAH was reduced vs placebo by 33\% (97.5\% CL: $3-54 \% ; \mathrm{P}=0.0146)$ in the macitentan $3 \mathrm{mg}$ group and $50 \%$ (97.5\% CL: 25-67\%; P $<0.0001$ ) in the macitentan $10 \mathrm{mg}$ group. Risk of hospitalisation for $\mathrm{PAH}$ was reduced by $39 \%$ (97.5\% CL: $10-58 \% ; \mathrm{P}=0.0040$ ) with macitentan $3 \mathrm{mg}$ and 50\% (97.5\% CL: 24-66\%; P = 0.0001) with macitentan $10 \mathrm{mg}$. Overall, 33\% ( $\mathrm{n}=82), 23 \%(\mathrm{n}=58)$, and 20\% $(\mathrm{n}=49)$ of patients randomised to placebo, macitentan $3 \mathrm{mg}$, and macitentan 10mg, respectively, were hospitalised at least once for PAH. Compared with placebo, the rate of PAH-related hospitalisations and number of inpatient hospital days per year were reduced by 43\% $(\mathrm{P}=0.0068)$ and 33\% $(\mathrm{P}=0.2707)$, respectively, with macitentan $3 \mathrm{mg}$, and by $55 \% \quad(\mathrm{P}=0.0002)$ and $52 \%$ $(\mathrm{P}=0.0416)$, respectively, with macitentan $10 \mathrm{mg}$ (Table). Macitentan was well tolerated, with similar incidences of elevated liver aminotransferases and peripheral oedema across groups. Adverse events more frequently associated with macitentan vs placebo were headache, nasopharyngitis, and anaemia.

Conclusions Macitentan significantly reduced the risk of hospitalisation for PAH and the number of PAH-related hospitalisations and inpatient days (10mg only). These data offer further evidence that macitentan has beneficial effects on long-term outcomes in PAH.

\begin{tabular}{|c|c|c|c|}
\hline & $\begin{array}{l}\text { Placebo } \\
\mathrm{N}=249\end{array}$ & $\begin{array}{l}\text { Macitentan } \\
3 \mathrm{mg} \\
\mathrm{N}=250\end{array}$ & $\begin{array}{l}\text { Macitentan } \\
10 \mathrm{mg} \\
\mathrm{N}=242\end{array}$ \\
\hline \multicolumn{4}{|l|}{ PAH-related hospitalisations per year } \\
\hline Adjusted* annual rate per & $27(20-36)$ & $15(11-21)$ & $12(9-17)$ \\
\hline \multicolumn{4}{|l|}{100 patient-years (95\% CL) } \\
\hline Treatment effect vs placebo $(95 \% \mathrm{CL})$ & & $0.57(0.38-0.86)$ & $0.45(0.30-0.69)$ \\
\hline P-value & & 0.0068 & 0.0002 \\
\hline \multicolumn{4}{|c|}{ PAH-related inpatient hospitalisation days per year } \\
\hline Adjusted* annual rate $(95 \% \mathrm{CL})$ & $5.5(3.3-9.0)$ & $3.7(2.2-6.1)$ & $2.7(1.6-4.4)$ \\
\hline Treatment effect vs placebo $(95 \% \mathrm{CL})$ & & $0.67(0.33-1.37)$ & $0.48(0.24-0.97)$ \\
\hline P-value & & 0.2707 & 0.0416 \\
\hline
\end{tabular}

*Adjusted in a negative binomial regression model for WHO functional class (I/II vs III/IV) and 6-minute walk distance at baseline (>380 $\mathrm{m}$ vs $\leq 380 \mathrm{~m}$ )

CL: confidence limit; PAH: pulmonary arterial hypertension

\section{P150 TREATMENT OF PULMONARY EMBOLISM IN ACTIVE MALIGNANCY - PRESCRIBING PRACTICES AMONGST PHYSICIANS}

MR Kavu, M Coates, NM Cummings; University Hospital of North Durham, Durham, United Kingdom

\subsection{6/thoraxjnl-2013-204457.300}

Introduction Pulmonary embolism (PE) is a common complication of malignancy. NICE guidance for the treatment of venous thromboembolism (VTE) issued in June 2012 recommended that those with active cancer and confirmed PE be treated with low molecular weight heparin $(\mathrm{LMWH})$ rather than alternative anticoagulants. ${ }^{1}$ We assessed whether this guidance is being adhered to in our Trust.

Methods A retrospective review of electronic discharge summaries was undertaken on those who were discharged from the two acute hospitals in our Trust (population 600,000) with a diagnosis of PE between July 2012 and June 2013, the 12 months following the publication of the NICE guidance. In addition, an anonymised, internet-based survey was undertaken of the 62 consultant physicians within the Trust, to determine which anticoagulant they would routinely prescribe for PE in active malignancy.

Results Within the 12 month period of this study, 298 patients (173 women, $125 \mathrm{men}$ ) survived to discharge, having had PE confirmed on imaging. Forty six of these were known to have malignancy and a further 13 were found to have cancer at the 